\title{
Animosity and Community Size Correlation in Bilingual Telephonic Interactions between Customer/Social Service Representatives and Hispanic Clients: Understanding How Hispanic Community Size Affects Hostility Levels in Customer and Social Services from State to State
}

Scarllet Bautista

Portland State University

Follow this and additional works at: https://pdxscholar.library.pdx.edu/anthos

Part of the Work, Economy and Organizations Commons

Let us know how access to this document benefits you.

Recommended Citation

Bautista, Scarllet (2014) "Animosity and Community Size Correlation in Bilingual Telephonic Interactions between Customer/Social Service Representatives and Hispanic Clients: Understanding How Hispanic Community Size Affects Hostility Levels in Customer and Social Services from State to State," Anthós: Vol. 6: Iss. 1, Article 2.

https://doi.org/10.15760/anthos.2014.3

This open access Article is distributed under the terms of the Creative Commons Attribution-NonCommercialShareAlike 4.0 International License (CC BY-NC-SA 4.0). All documents in PDXScholar should meet accessibility standards. If we can make this document more accessible to you, contact our team. 


\section{Animosity and Community Size Correlation in Bilingual Telephonic Interactions between Customer/Social Service Representatives and Hispanic Clients: Understanding How Hispanic Community Size Affects Hostility Levels in Customer and Social Services from State to State}

Scarllet Bautista

The purpose of this research is to understand how the Hispanic community size affects the telephonic interactions between FEP (Fluent English Proficient) customer/social service representatives and LEPs (Limited English Proficient). I hypothesize that the larger the Hispanic community in a state, the more tense bilingual telephonic interactions will be. I evaluated a total of 179 English/Spanish consecutive interpreting calls over the course of nine days. I took note and counted various aspects of the interaction: voice, use of profanity, use of sarcasm to express disgust and sudden telephone hung ups from the LEP customer/client and attitude, tone, use of pleasantries, listening/allowing the LEP to talk, interest to help and whether additional assistance was offered from the representative, and also call state and nature of the call. I found 92 percent of the time, the larger Hispanic community representation in the state where the call originated, the more animosity ridden was the telephonic interaction. The reason for this correlation might be rooted on different factors such as the LEP desire to conduct business in their own language and the representative desire to keep their 
Anthós, Vol. VI, Issue 1

workplace a monolinguistic environment. Further study is needed to establish causation.

\section{Background}

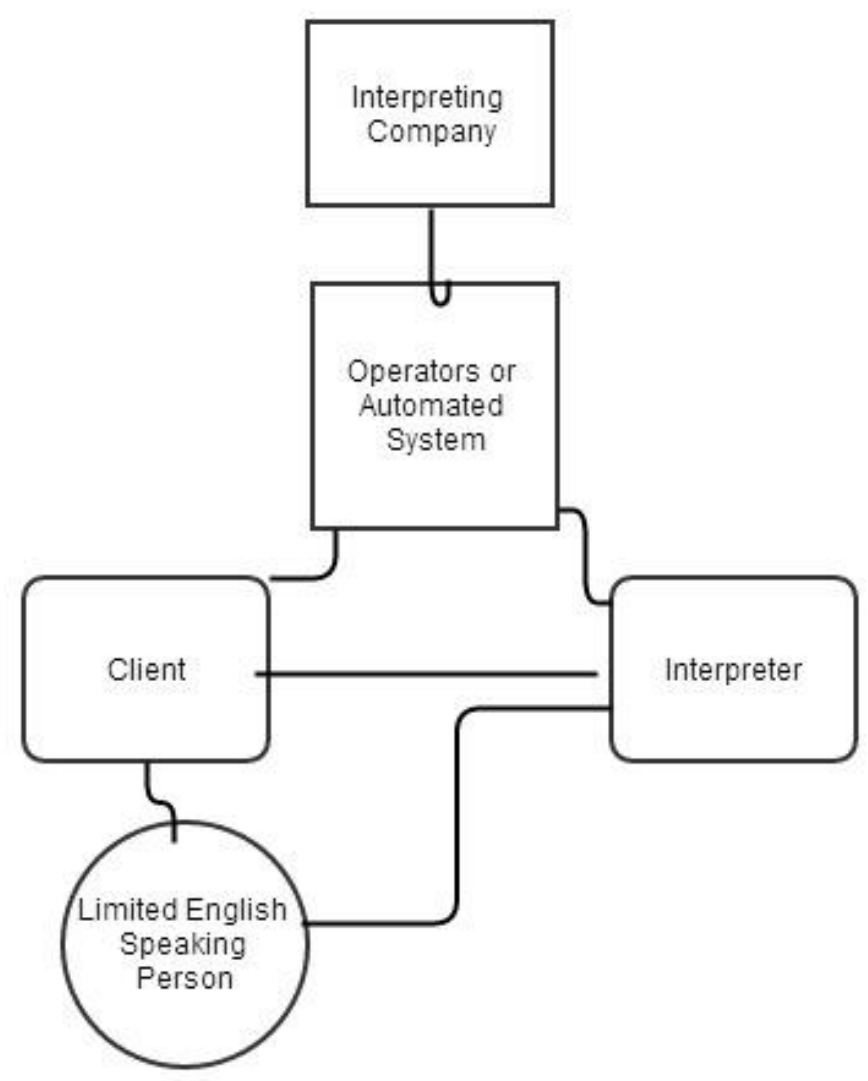

Figure 1. This relationship map reflects the components and flow of an interpreting call and how they relate to one another.

\section{Social Network}

At the very top, there is the interpreting company that hires operators, contracts and sometimes hires interpreters, sells the interpreter services and provides technology used to connect their 
customers with the interpreter for the requested language. The operator and/or the automated system answer customers' calls, call the interpreter and put them in a conference call. Sometimes the operators also place third party "dial outs" in order to bring the LEP (Limited English Person) into the conference. The interpreters provide consecutive two-way interpretation, the equipment needed to provide a clear phone connection, a computer to receive memos, training material from the operators and interpreting company via email, and they $\log$ in and out of the phone system.

\section{Demography}

Mostly Hispanic in origin, the interpreters tend to be second generation immigrants with a higher level of education than the LEP's. Although there are exceptions, most LEP's are first generation immigrants, low income, often performing seasonal work. About 75 percent of the LEP's are from Mexico. Since my clients, the interpreter companies, provide services to social and financial support government agencies, most of the LEP's are young females who are single mothers.

\section{Hispanic Community Presence in the United States}

In 2010, the states with the largest Latino populations were California (14 million), Texas (9.5 million), Florida (4.2 million), New York (3.4 million), and Illinois (1.2 million). According to the Bureau of Labor Statistics, as of June 2012 Latinos represented 16 percent of the U.S. labor force, at nearly 25 million workers. By 2018, it is projected that Latinos will make up 18 percent of the workforce. For Latinos, as is the case for all Americans, place of residence also affects employment rates. States with the highest levels of unemployment for Latinos include California, Arizona, Illinois, New York, Florida, and Texas. It is no surprise that the states with the largest Latinos population have larger number of Latino employees. Latinos are more likely to move within a county, indicating that they 
are more likely to move for employment opportunities (Centers for Disease Control and Prevention, 2010).

While the majority of U.S. residing Latinos are native-born U.S. citizens, there is a sizable population that is foreign-born, and a fraction of those lack legal status. Immigrants of North and South American origin comprise 9.7 million of the estimated 11.5 million unauthorized immigrants. Consequently, Congress's failure to pass comprehensive immigration reform has had a disproportionate effect on the Latino community. A total of 16.6 million people, many of Hispanic origin, live in mixed-status families with at least one unauthorized immigrant family member. Hence, the consequences of lack of legal status, including lower wages and barriers to higher education and medical care, adversely impact not only undocumented Latinos themselves but also their families and communities.

Research across the board has shown that racial and ethnic minorities, particularly Latinos, receive lower-quality health care, suffer worse health outcomes, and have higher rates of certain illnesses. Here are some of the most startling health disparities facing the Latino community:

- $\quad$ Hispanic children have the highest childhood obesity rate in the country, with about two in five Hispanic children aged two to 19 being overweight or obese (Let's Move!).

- Latinas are twice as likely to die from pregnancyassociated complications as their white counterparts (Arons \& Agenor, 2010).

- Latinos are also disproportionately affected by HIV/AIDS and are three times more likely than their white counterparts to be infected. (Centers for Disease Control and Prevention, 2012).

- $\quad$ Latinas are 20 percent more likely to die from breast cancer than their white counterparts. (Centers for Disease Control and Prevention, 2012). 
- $\quad$ Latinos exceeded all other racial or ethnic groups with the largest percentage (29 percent) of reported tuberculosis cases in the United States in 2010. (Centers for Disease Control and Prevention, 2012).

- Half of all Latino children born in 2000 are at risk of developing diabetes. (Centers for Disease Control and Prevention, 2010).

As a result of continuous immigration over the last 30 years, as well as the historical back-and-forth migration of MexicanAmericans and Puerto Ricans and more recently of other national groups, Latinos immigrants have held onto the Spanish language over more generations than any other group in history. 90 percent of U.S Latinos speak Spanish. In contrast, speakers of Italian dwindled by 94 percent from the second to the third generation of immigrants. There is no one explanation for why Latinos have maintained the language whereas other immigrant groups have not. The result, however, is the creation of a distinctly new and hybrid Latino-American culture which has impacted the United States as much as it has impacted Latinos: "soon the United States will have the second largest number of Spanish-speakers in the world" (David Rockefeller Center for Latin American Studies).

Last July, the California Historical Resources Commission nominated the complex of Our Lady Queen of Peace -- more commonly known as Nuestra Señora Reina de La Paz - located in Keene, California, for inclusion on the list of Hispanic sites in the National Register of Historic Places. This site is the burial ground of legendary Latino labor rights leader, Cesar Chavez, and the union headquarters of his farm workers movement, the United Federation of Workers. It is also a conference and cultural center (Lerner, 2012). 
Anthós, Vol. VI, Issue 1

Most Influential Hispanics in America According to TIME Magazine:

- Alberto Gonzales

- Mel Martinez

- Lionel Sosa

- $\quad$ Antonio Gonzalez

- Antonio Villaraigosa

- Cristina Saralegui

- Gustavo Santaolalla

- Robert Rodriguez

- $\quad$ Alisa Valdes-Rodriguez

- Anthony Romero

- Arturo Moreno

- George Lopez

- Jennifer Lopez

- Jorge Perez

- Mari Carmen Ramírez

- Narciso Rodriguez

- Aida Giachello

- Bill Richardson

- Jorge Ramos

- Pablo Alvarado

- Mario Molina

- Jose Gomez

- Salma Hayek

- Sara Martinez Tucker

- Ysrael Seinuk

- Mel Martinez

- Lionel Sosa

- Antonio Gonzalez

- Antonio Villaraigosa 
- Cristina Saralegui

- Gustavo Santaolalla

- Robert Rodriguez

- $\quad$ Alisa Valdes-Rodriguez

- Anthony Romero

- Arturo Moreno

- George Lopez

- Jennifer Lopez

- Jorge Perez

- Mari Carmen Ramírez

- Narciso Rodriguez

- Aida Giachello

- Bill Richardson

- Jorge Ramos

- Pablo Alvarado

- Mario Molina

- Jose Gomez

- Salma Hayek

- $\quad$ Sara Martinez Tuck

\section{Selection Criteria}

Interpreting companies were selected for this study based off the diversity of their clientele, number of states serviced, diversity of issues covered by their calls, and call flow. The types of calls evaluated included: courts, federal agencies, federal and state welfare, insurance companies, financial institutions, hospitals, technical support, clinics, correctional facilities, pharmacies, etc.

\section{Method}

Nationwide calls were examined for various components that point to empathy and good customer/social service: 
- Attitude from client LEP towards the representative FEP and the interpreter were evaluated and tallied.

- The client LEP input was graded by adding a negative tally every time they: raised their voice, used profanity, used sarcasm to express disgust, threatened the representative or abandoned the call unexpectedly.

- The customer/social service representative FEP was graded by adding tallies for demonstrating good customer service and subtracting tallies for opposite actions on the following good customer service criteria: attitude (tone of voice, use of pleasantries, being courteous), active listening (allowing the LEP to state their issue), interest in helping LEP (showing empathy) and if they offered additional assistance.

- Note was taken of the LEP's state and the nature of the calls.

- Excel tables were developed to plot the data collected.

- At the end of the data collection, the tallies of each state were added and divided by the number of calls to obtain averages.

- The tally averages were then compared to the percentage of Hispanics in those states.

- The following U.S. map of Hispanic population was used:

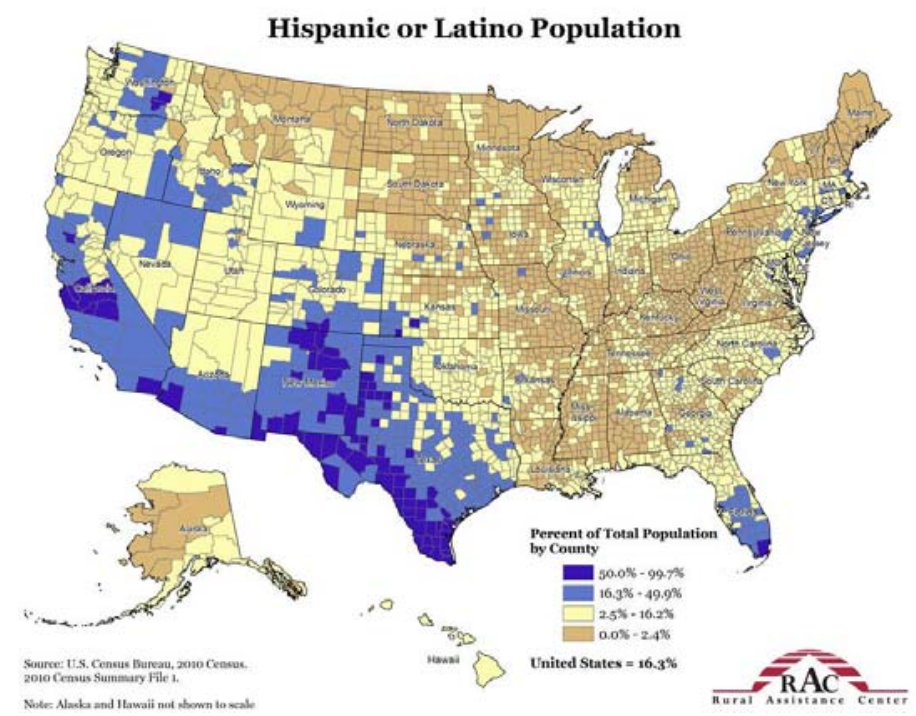




\section{Results}

The states with the highest scores are: Minnesota with an average of 10 tallies (0-2.4\% Hispanic population in most counties), followed by Washington with an average of eight tallies (2.5-16.2\% Hispanic population in most counties) tied with Alaska with an average of eight tallies (0-2.4\% Hispanic population in most counties).

The states with the lowest scores are: Texas with an average of one tally (16.3-49.9\% Hispanic population in most counties), followed by California with an average of two tallies (16.3-49.9\% Hispanic population in most counties) and Florida with an average of three tallies (16.3-49.9\% Hispanic population in most counties).

There is also a correlation between ethnic tension and lower stratification tier of the LEP. The states that show the most hostilities towards the LEP tended to have calls be related to health problems and unemployment. Washington LEP's tend to place calls regarding child care, child support, financial institutions, insurance claims and rarely illness.

\section{Conclusion}

This study provides the first evidence of correlation of animosity in telephonic interactions between customer service/social service representatives and Hispanic clients and size of the ethnic community. Using a manual tracking technique, I documented the hostility between limited English speakers and customer/social service workers. Increased levels of hostility were found to be associated with bigger sized ethnic communities. Interaction tension between LEP clients/customers and LFP customer service/social service representatives in bilingual telephone calls can be predicted with a high degree of accuracy by the size of the LEP population in the region. There is a negative correlation between Hispanic community size and degree of satisfaction and quality customer/social service: the bigger the Hispanic community in a state, the lower the satisfaction and quality of customer/social service. The states with the lowest 
Anthós, Vol. VI, Issue 1

customer service grades are also the most stratified. Exploration on the causation of these correlations is needed to help lower the level of aggression between LEPs and FEPs telephonic communication.

Notably, decreased quality-of-life in the Hispanic community has also been found to be associated with the hostility of these interactions. Further, a research study published in Development Psychology examined 876 Hispanic, African American and Asian American students over time. Conducted by Aprile D. Benner of the University of Texas at Austin and Sandra Graham of the University of California at Los Angeles, the study examined some of the ecological factors surrounding discrimination and its outcomes. As Benner and Graham predicted, statistical analysis of the survey data showed increased ethnic diversity in school led to strong racial and ethnic tension. How minority youths see the racial climate depends on what kinds of signals they receive from the people around them. However, how adults and heads of heads of households perceive hostile signals remains unknown. Although I do not fully understand the relationship between the structure and functioning of these telephonic interactions, mounting evidence suggests that increased size of Hispanic community does invariably predict increased hostility; in fact, smaller Hispanic communities have been found to be associated with increased quality of life and economic prosperity of the community at-large. Further research is needed to relate the current findings of smaller Hispanic communities to alterations in the interactions with social and customer services and how different tension sources affect the LEP. Examining these interactions would allow us to gain better understanding of the dynamics relating to social services and Hispanic community structures and functioning. The effect of a belligerent status on a Hispanic community may be mediated, in part, by support of social service programs designed to defuse ethnic tension in government and private companies at a quality assurance level. As Benner and Graham point out in their summary: "Ours is a society in which the racial/ethnic diversity of the under-18 population is 
increasing dramatically, in which gay and lesbian youth are initiating the coming-out process at younger ages, and in which childhood obesity is growing at alarming rates. Yet we also live in a society where racial prejudices, homophobic attitudes, and anti-obesity sentiments run deep." Intervening to reduce these tensions is an important part of promoting mental health for all.

\section{References}

Arons, J. \& Agénor, M. (2010). Separate and Unequal: The Hyde Amendment and Women of Color. Retrieved from: http://www.americanprogress.org/issues/ women/report/2010/12/06/8808/separate-and-unequal/

Benner, A. D. \& Graham, S. (2013). The Antecedents and Consequences of Racial/Ethnic Discrimination during Adolescence: Does the Source of Discrimination Matter?. Developmental Psychology, 49(8), 1602-1613. doi: 10.1037/a0030557

Cárdenas, V. \& Kerby, S. (2012). The State of Latinos in the United States: Although This Growing Population Has Experienced Marked Success, Barriers Remain. Retrieved from: http://www.americanprogress.org/issues/ race/report/2012/08/08/11984/the-state-of-latinos-in-the-united-states/ Centers for Disease Control and Prevention. (2014). Health Disparities in HIV/AIDS, Viral Hepatitis, STDs, and TB: Hispanics/Latinos. Retrieved from: http://www.cdc.gov/nchhstp/healthdisparities/Hispanics.html

David Rockefeller Center for Latin American Studies. Background Information for

Teachers. Retrieved from: http://www.fas.harvard.edu/ gstudies/latin/lessons/ backgd.htm

Ervin-Tripp, S. (1964). An Analysis of the Interaction of Language, Topic, and Listener. American Anthropologist, 66(6). Retrieved from: http://www.jstor .org/stable/668163

Grosjean, F. (2010). Bilingual: Life and Reality. Cambridge, MA: Harvard University Press.

Grosjean, F. List of Published Posts by Content Area. Retrieved from: http:// www.francoisgrosjean.ch/blog_en.html

Lerner, G. (2012). National Parks: Chronicling the Presence and Historic Legacy of U.S. Hispanics. Retrieved from: http://www.huffingtonpost.com/2012/02/ 02/ national-parks-hispanics_n_1251685.html

Let's Move!. The Facts for Hispanics. Retrieved from: http://www.letsmove.gov/ sites/letsmove.gov/files/Let\%27s_Move_Fact_Sheet_for_Hispanics.pdf. Minnesota Department of Administration. (2005). Minnesota Population 
Anthós, Vol. VI, Issue 1

Projections by Race and Hispanic Origin. Retrieved from: http://www. demography.state.mn.us/resource.html? $\mathrm{Id}=10960$

TIME. 25 Most Influential Hispanics in America. Retrieved from: http://content .time.com/time/specials/packages/0,28757,2008201,00.html

U.S. Census Bureau. (2010). [Map of the U.S. Hispanic or Latino population percentage by county]. Hispanic or Latino Population. Retrieved from: http://www.raconline.org/racmaps/mapfiles/hispanic.jpg

U.S. Census Bureau. (2014). QuickFacts: Minnesota. Retrieved from: http:// quickfacts.census.gov/qfd/states/27000.html 